\title{
PLASTIC FLOW PRODUCED BY SINGLE ION IMPACTS ON METALS*
}

\author{
R. C. Birtcher \\ Materials Science Division \\ Argonne National Laboratory \\ 9700 S. Cass Ave. \\ Argonne, IL 60439 \\ S. E. Donnelly \\ Joule Physics Laboratory \\ University of Salford \\ Manchester M5 4WT, UK \\ October 1998

The submitted manuscript has
been created by the University of
Chicago as Operator of Argonne
National Laboratory (Argonne'
under Contract No. W-31-109.
ENG-38 with the U.S. Department
of Energy. The U.S. Govemmen!
retains for itself, and others
acting on its behaft, a paid-up,
non exclusive, irrevocable
worldwide license in said article
to reproduce, prepare derivative
works, distribute copies to the
public, and perform publicly and
display publicly, by or on behali
of the Government.

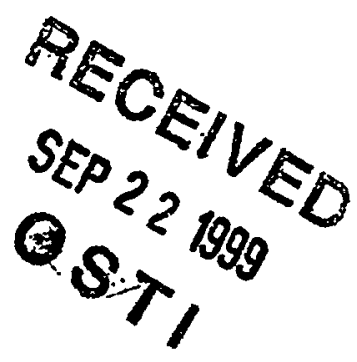

Submitted to the 11th International Conference on Ion Beam Modification of Materials, August 31 - September 4, 1998, Amsterdam, The Netherlands.

*Work supported by the U. S. Department of Energy, Office of Basic Energy Sciences, under Contract W-31-109-Eng-38 at Argonne National Laboratory and by a collaborative research grant number 910760 from NATO. 


\section{DISCLAIMER}

This report was prepared as an account of work sponsored by an agency of the United States Government. Neither the United States Government nor any agency thereof, nor any of their employees, make any warranty, express or implied, or assumes any legal liability or responsibility for the accuracy, completeness, or usefulness of any information, apparatus, product, or process disclosed, or represents that its use would not infringe privately owned rights. Reference herein to any specific commercial product, process, or service by trade name, trademark, manufacturer, or otherwise does not necessarily constitute or imply its endorsement, recommendation, or favoring by the United States Government or any agency thereof. The views and opinions of authors expressed herein do not necessarily state or reflect those of the United States Government or any agency thereof. 


\section{DISCLAIMER}

Portions of this document may be illegible in electronic image products. Images are produced from the best available original document. 
PLASTIC FLOW PRODUCED BY SINGLE ION IMPACTS ON METALS

\author{
R. C. BIRTCHER\$ and S. E. DONNELLY\#
}

\$ Materials Science Division, Argonne National Laboratory, Argonne, IL. 60439, USA

\# Joule Physics Laboratory, University of Salford, Manchester M5 4WT, UK

Single ion impacts have been observed using in situ transmission electron microscopy and video recording with a time resolution of 33 milliseconds. Gold was irradiated at $50 \mathrm{~K}$ and room temperature. Single ion impacts produce holes, modify existing holes, and extrude material into the initial specimen hole and holes formed by other ion impacts. The same behavior is observed at both temperatures.

At both temperatures, ion impacts result in craters and ejected material. Ion impacts produce more small craters than large ones for all ion masses, while heavier mass ions produce more and larger craters than lighter mass ions. This comparison is affected by the ion energy. As the energy of an ion is increased, the probability for deposition near the surface decreases and fewer craters are formed. For a given ion mass, crater production depends on the probability for displacement cascade production in the near surface region. Crater and holes are stable at room temperature, however, ion impacts near an existing crater may cause flow of material into the crater either reshaping or annihilating it.

Holes and craters result from the explosive outflow of material from the molten zone of near-surface cascades. The outflow may take the form of molten material, a solid lid or an ejected particle. The surface is a major perturbation on displacement cascades resulting from ion impacts. 


\section{INTRODUCTION}

Decades of radiation effects study have concentrated on displacement events totally contained within materials. With the exception of sputtering, this has also been true for the study of ion solid interactions. Efforts have centered on understanding defect production and the microstructural changes caused by defects. In general, out of the thousands of atoms involved in a high energy displacement event, most recombine so that the result is one to two hundred defects localized in a defect cascade [1]. At elevated temperatures only a few percent of these defects are responsible for diffusion related changes [2].

It has long been known that many metals undergo major changes in the surface topology during ion bombardment. In this paper we report on a massive effects of single ion impacts on the surfaces of dense metals. Such effects include craters and particles as observed on ion irradiated gold [3] and molybdenum [4]. These effects play a major role in evolution of surfaces under irradiation. Our emphases has been on Xe irradiation of gold, and irradiations have been done at room temperature and $50 \mathrm{~K}$. 


\section{EXPERIMENTAL}

Ion irradiations were carried out in a Hitachi A-9000 transmission electron microscope (TEM) operating at $300 \mathrm{keV}$ at the IVEM/Accelerator Facility located at Argonne National Laboratory [5]. In the IVEM/Accelerator Facility, the ion beam is oriented $30^{\circ}$ from the microscope axis. All specimen were tilted $15^{\circ}$ towards the ion beam so that both ions and electrons were incident on the specimen at $15^{\circ}$ to the foil normal. Specimens were irradiated with $\mathrm{Xe}^{+}$ions at energies in the range $50-400 \mathrm{keV}$ at dose rates between $10^{10}$ and $10^{12}$ ions $/ \mathrm{cm}^{2} / \mathrm{s}$. Images from a Gatan 622 video camera and image-intensification system were recorded on video tape with a time resolution of $33 \mathrm{~ms}$ (a single video frame).

TEM Specimens were produced from rolled, annealed foils with a 99.999 purity from which $3 \mathrm{~mm}$ discs were punched and electrochemically thinned. In addition, thin Au films were made by thermal evaporation of 99.999 at \% pure starting material onto $\mathrm{NaCl}$ at a temperature of $350^{\circ} \mathrm{C}$. This resulted in a largely monocrystalline film with a $<100>$ surface normal. The gold films were determined by Rutherford backscattering to have a thickness of $62 \pm 2 \mathrm{~nm}$. The thickness of specimens fabricated from bulk material was not accurately known but was of the order of $50 \mathrm{~nm}$ or less.

Holes and craters are made visible in TEM in the same way as voids and bubbles by means of their phase-contrast under controlled amounts of objective lens defocusing. To enhance visibility, images are obtained in bright field from a region of the somewhat bent films in which no Bragg reflection is strongly excited. Under these conditions, underfocussing the objective lens by typically 700 to $1000 \mathrm{~nm}$ yields reasonably sharp images in which the crater is lighter than 
the background and is delineated by a dark Fresnel fringe. Similarly a small mound or particle on the surface appears darker than the background with a light fringe around it.

Atomic recoil from an ion impact occurs on a time scale of picoseconds which can not be resolved using TV rate recordings. However by using low ion fluxes, it is possible to separate impact events in time and distance so that the consequences of single impacts can be recorded and analyzed. Typical ion fluxes used in this work result in a ion impact each second in an area $30 \mathrm{~nm}$ on a side. During this time 30 video frames are recorded. Frame by frame examination is used to identify the sites of individual ion impacts. 


\section{RESULTS}

\section{Au IRRADIATED at ROOM TEMPERATURE}

One of the most striking example of changes in the surface topology during ion bombardment is the production of holes [6] and craters [3,7] by single ion impacts. Holes made by single ion impacts are shown in figure 1 for very thin, wedge shaped $\mathrm{Au}$ irradiated at room temperature with $200 \mathrm{keV} \mathrm{Xe}$ ions. An ion strikes the entire area shown in figure 1 on average every 10 frames or $0.3 \mathrm{~s}$ which is much longer than the cascade lifetime of a few tens of picoseconds. The contrast within the holes is due to noise in the imaging system. The shape of the hole is recorded long after the cascade that produced it has ended and thus includes any annealing that occurs during cascade quenching.

The initial hole in figure 1-A is equal-axed and faceted. In figures 1-B a single ion impact has injected material into the first hole changing its size and shape. Typically, initial isolated holes appear equal-axed, but additional ion impacts change their shape. In figure 1-C a single ion impact has enlarged the hole. Figure 1-D shows a new hole appearing next to the first hole, and flow of material from the new hole reduces the size of the first hole. Assuming a foil thickness between 20 to $50 \mathrm{~nm}$, between 20,000 to 50,000 gold atoms were involved in the creation of either hole. This would imply in an enormously high sputtering yield if the atoms were ejected from the gold surface. However, the change in image contrast suggest that these atoms have been moved onto the surface. Although material expelled from an ion impact is more likely to be closely associated with a hole, occasionally particles appear far from any hole or crater. 
Continued irradiation of the area shown in figure 1 resulted in another hole, figure 2-A. Another single ion impact injected a finger of material into the perforation formed during specimen preparation (arrow figure 2-B). This occurred without another hole being formed. Although holes may be enlarged or shrunk by ion impacts, the net trend is hole growth. Additional holes formed in the area shown in figure 3-B until the large hole on the left of figure 3-B is formed. The perforation made during specimen preparation is on the right. In frame 3-C an ion impact removed a large amount of material (marked by an arrow) from the edge of the left hole. In frame 3-D an impact cut the small strip of material between the two holes (marked by an arrow), and a second impact formed a bump on the side of the resultant finger (marked by an arrow). In frame 3-E the upper finger reformed by plastic flow after an ion impact. In frame 3-F the tip of the extended material reformed into a more rounded shape (marked by an arrow). All changes occurred in discrete steps. Also evident in the images are craters produced by single ion impacts.

It has been a long-standing observation in our laboratories that thin areas of irradiated specimens disappear and holes in apertures enlarge. This is a consequence of plastic flow during heavy-ion irradiation. The dynamics of this process are shown in figure 3. Frame-by-frame analysis of our in-situ observations reveal that the thickening occurs in pulses as a result of ion-beam induced plastic flow. When observed at a high dose-rate this process appears to be similar to changes that occur when thin gold foils are heated to close to the bulk melting temperature and surface tension forces cause the material to flow. When the ion irradiation is stopped flow of material ceases and there is no further change to the morphology of the gold foil.

\section{Au IRRADIATED at $50 \mathrm{~K}$}


Examples of single $200 \mathrm{keV} \mathrm{Xe}$ ion impacts on $\mathrm{Au}$ at $50 \mathrm{~K}$ are shown in extractions from a video recording, figure 4. All events shown occurred in the time interval between the capture of two successive video frames. Figure 4-A shows the edge of the initial perforation in the specimen before irradiation. After start of the irradiation a hole appeared, figure 4-B. This hole remained intact until another nearby ion impact produced a new hole and injected material, arrowed in figure 4-C. Another ion impact, figure 4-D, ejected material from the edge of the specimen into the initial perforation in the specimen. The affect of a single ion impact on a protrudence into the initial perforation in the specimen, located in an area slightly separated from that shown in Figure 4-A, is shown in figure 4-E and 4-F. When the ion irradiation is stopped flow of material ceases and there is no further change to the morphology of the gold foil. The same behavior is observed at $50 \mathrm{~K}$ as is observed at room temperature.

Deformations at the edges of holes or the specimen result from plastic flow of material away from the site of an ion impact. In general, filling of holes does not depend on a second hole being near, and frequently the impact event responsible for a change does not itself produce a visible feature. During the quenching phase of the molten zone, surface tension forces will act on any free surfaces involved with the melt zone. This gives rise to the over all tendency for holes to enlarge. Although extruding of material into holes is observed, changes in the shape of edges tend to make the specimen thicker.

\section{CRATER PRODUCTION}

Although the creation of holes by single ion impacts is the most spectacular event, the most common event is the production of craters on the surface [7]. This is displayed for thin films of $\mathrm{Au}$ in figure 5. Such craters result from 
dense, near-surface displacement cascades. Modeling suggest that they occur by a reflection of the cascade momentum back through the surface [8].

Although all craters are stable at room temperature with the ion beam turned off, ion impacts following crater creation lead to crater annihilation in one or more discrete steps. In some cases this is seen to occur as a consequence of plastic flow from a neighbouring impact site but in many cases the impact giving rise to annihilation or partial annihilation of a crater is not observed. This process is the same as associated with modification of holes. Small craters, less than $2-3 \mathrm{~nm}$ in diameter are generally annihilated in a single step. The crosssection for gold irradiated with $200 \mathrm{keV} \mathrm{Xe}$ ions is $85 \mathrm{~nm}^{2}$, i.e. an ion impact within a radius of approximately $5 \mathrm{~nm}$ of a small crater will annihilate the crater.

There can be significant transport of material from the ion impact site. Expelled material does not have the same shape as the crater from which it is ejected, implying that it has not been expelled as a solid piece. The form of the expelled material indicates that molten material has been expelled from the impact site and that surface tension forces have acted to produce forms ranging from an apparently quenched droplet to a separated and seemingly spherical particle. Regardless of whether or not the spatial and temporal dimensions of the spike are sufficient to permit the use of Maxwell-Boltzmann statistics, the images indicate that macroscopic concepts such as melting, flow in response to surface tension forces, and quenching provide a satisfactory description at $50 \mathrm{~K}$ or room temperature.

\section{DEPENDENCE ON ION MASS}

Craters may be produced on thin Au films by a range of ion masses and energies. Figure 5 shows examples of craters during irradiation with $\mathrm{Kr}, \mathrm{Xe}$ 
and $\mathrm{Au}$ ions. Also evident are particles that have been ejected during the irradiations. It is difficult to determine the number and sizes of craters produced by an ion from single images, but in general, ion impacts produce more small craters than large ones for all ion masses, while heavier mass ions produce more and larger craters than lighter mass ions. This comparison is affected by the ion energy. As the energy of an ion is increased the probability for large energy deposition near the surface decreases and fewer craters are formed. The important parameter is the rate of large energy transfers near the surface.

\section{SUMMARY}

The surface is a major perturbation on displacement cascades resulting from ion impacts. Ion impacts on dense materials result in major changes to the surface topology on the nanometer scale. These changes include the production of holes in very thin Au and craters on the surface. Although stable at room temperature, existing holes and craters are modify or annihilate by single ion impacts. Single ion impacts can extrude material from the specimen or hole edges. These effects occur in the same way at $50 \mathrm{~K}$ or room temperature. Flow from the melt zone of cascades is responsible for the observed changes.

\section{ACKNOWLEDGMENTS}

We thank B. Kestel for specimen preparation and E. Ryan, L. Funk, P. Baldo, T MacCormack and S. Ockers for assistance with the in-situ TEM experiments. This work has been supported by the U.S. Department of Energy, BES-Materials Sciences, under Contract W-31-109-Eng-38 and by a collaborative research grant number 910670 from NATO. One of us (SED) acknowledges funding from the Materials Science Division at Argonne National Laboratory that enabled him to spend a sabbatical at ANL. 


\section{REFERENCES}

1 J. A. Brinkman, Am. J. Phys. 24, 246, 1956.

2 L. E. Rehn and H. Wiedersich, Mat. Sci.. Forum 97-99, 43, 1992.

3 K. L. Merkle and W. Jâger, Phil. Mag, $\underline{\text { A44, 741, } 1981 .}$

4 M. L. Jenkins, and M. Wilkens, 1976, Phil. Mag. $\underline{34}, 1155$.

5 C. W. Allen, L. L. Funk, E. A. Ryan and S. T. Ockers, Nucl. Inst. and Meth. B 40/41, 553, 1989.

6 R. C. Birtcher and S. E. Donnelly, Phys. Rev. Lett. 77, 4374, 1996.

7 S. E. Donnelly and R. C. Birtcher, Phys. Rev. $\underline{56}, 13599,1997$.

8 R. S. Averback, M. Ghaly and H. Zhui, Mat. Res. Soc. Symp. Proc. Vol. $\underline{373}, 3,1995$.

9 T. S. Lin and Y. W. Chung, Sur. Sci. 207, 539, 1989.

10 J. F. Ziegler, J. P. Biersack and U. Littmark, The Stopping and Ranges of Ions in Solids, (Pergamon Press, New York 1985).

11 S. E. Donnelly and R. C. Birtcher, to be published in Phil. Mag. 1998. 


\section{FIGURES}

1 The change in holes in $\mathrm{Au}$ irradiated with $200 \mathrm{keV} \mathrm{Xe}$ ions at $300 \mathrm{~K}$. The images are captures from a video recording and are lettered in increasing time.

2 Extrusion of material from the edge Au irradiated at $300 \mathrm{~K}$ by $200 \mathrm{keV} \mathrm{Xe}$ ions. The images are captures from a video recording and are lettered in increasing time.

$2 \mathrm{Au}$ irradiated at $300 \mathrm{~K}$ by $200 \mathrm{keV} \mathrm{Xe}$ ions. The images are captures from a video recording and are lettered in increasing time.

$4 \mathrm{Au}$ irradiated with $200 \mathrm{keV} \mathrm{Xe}$ ions at $50 \mathrm{~K}$. The images are captures from a video recording, and the images are lettered in increasing time.

5 Au thin film irradiated at $300 \mathrm{~K}$ by (a) $200 \mathrm{keV} \mathrm{Kr}$ ions; (a) $200 \mathrm{keV} \mathrm{Xe}$ ions, (a) $200 \mathrm{keV} \mathrm{Au}$ ions, and (a) $400 \mathrm{keV} \mathrm{Au}$ ions. 

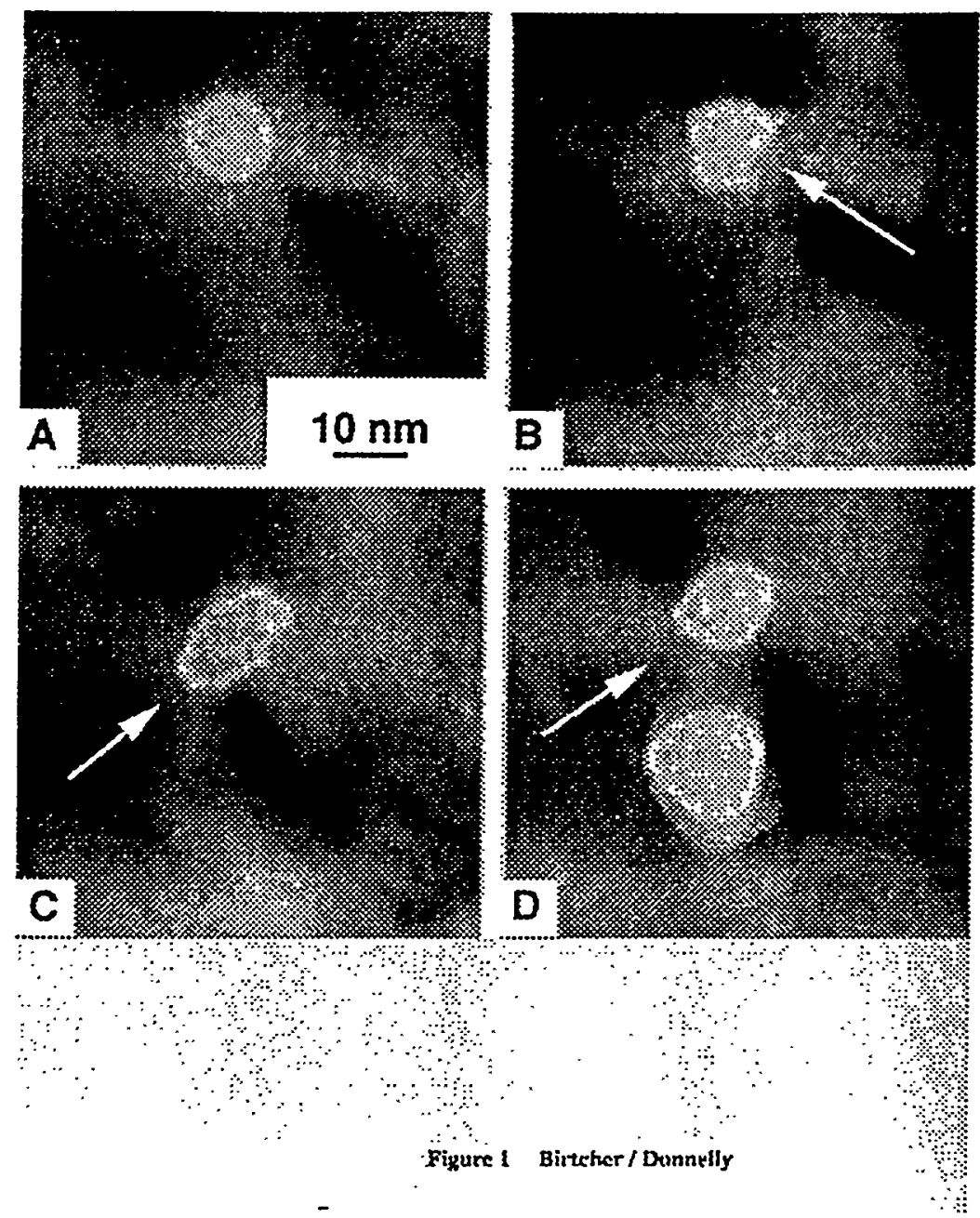


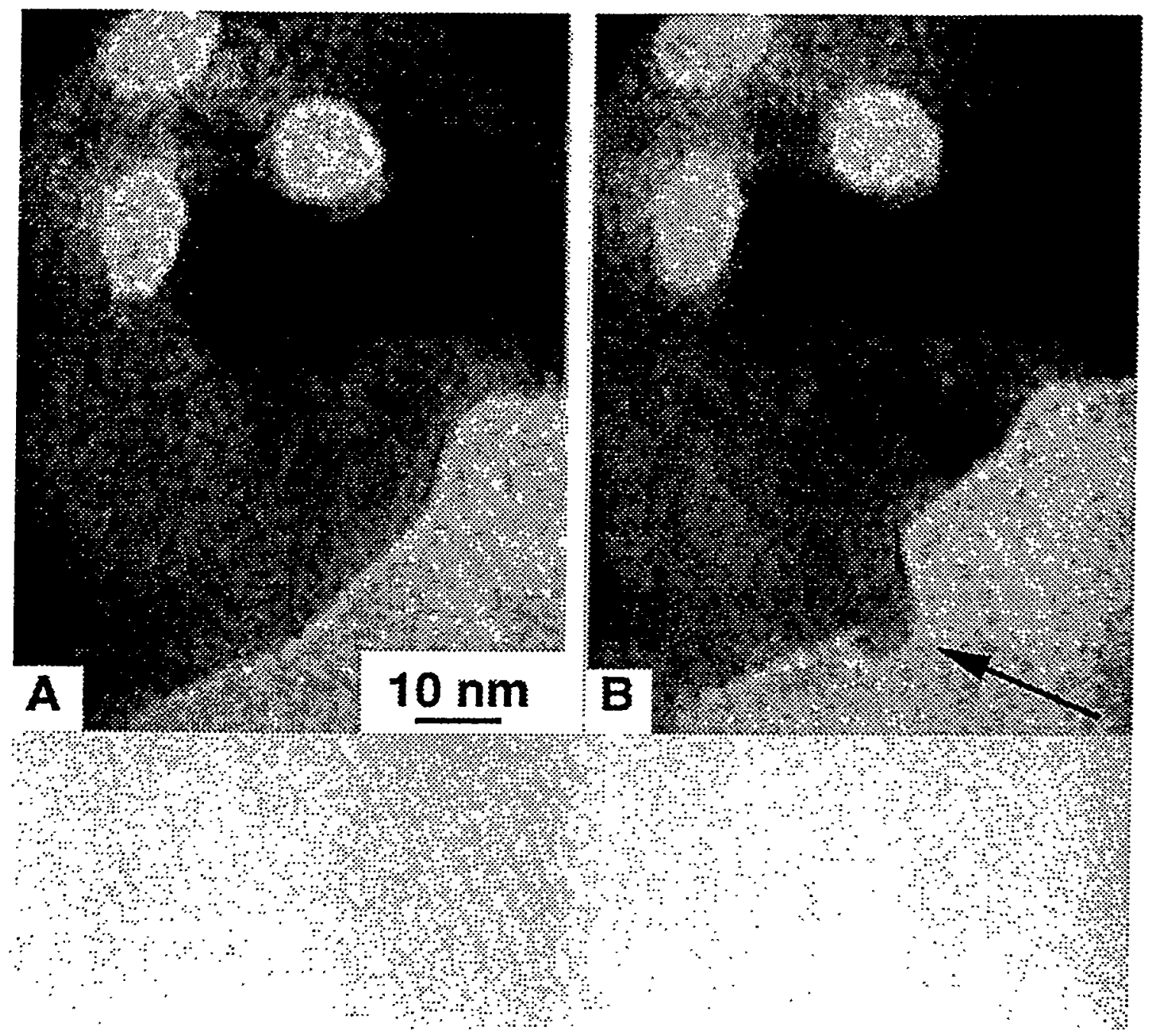

Figure 2 Birteher / Donnelly 


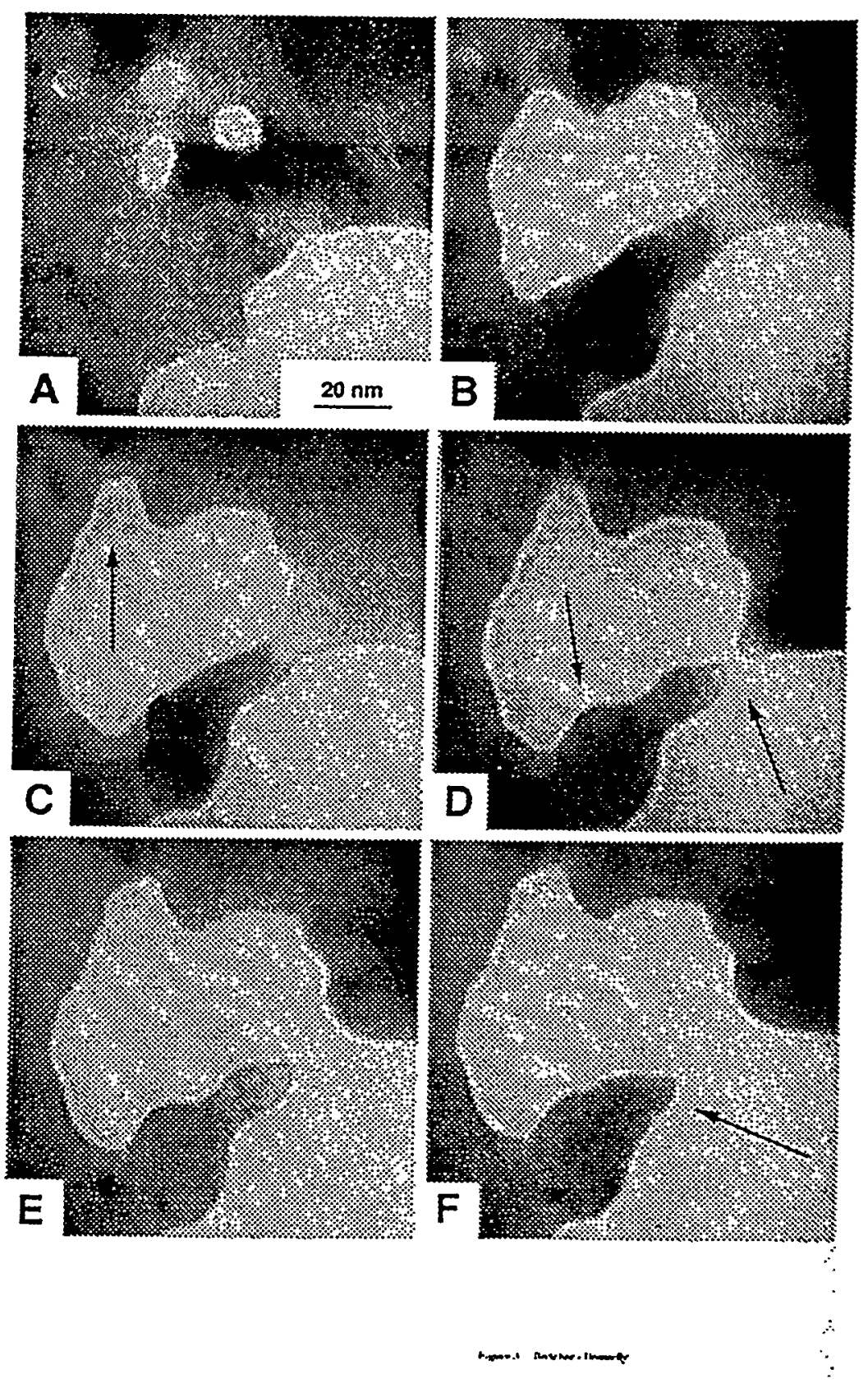




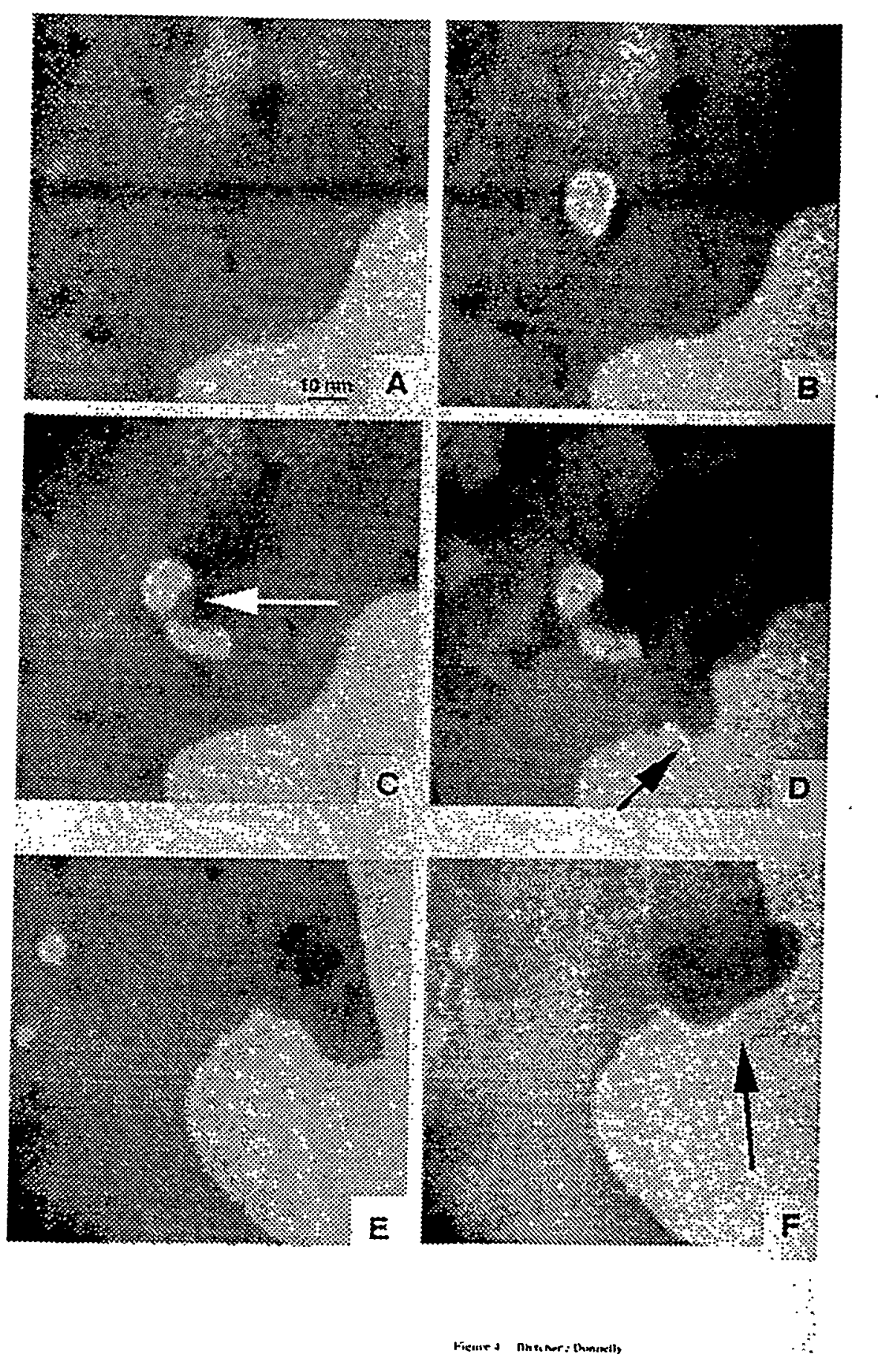




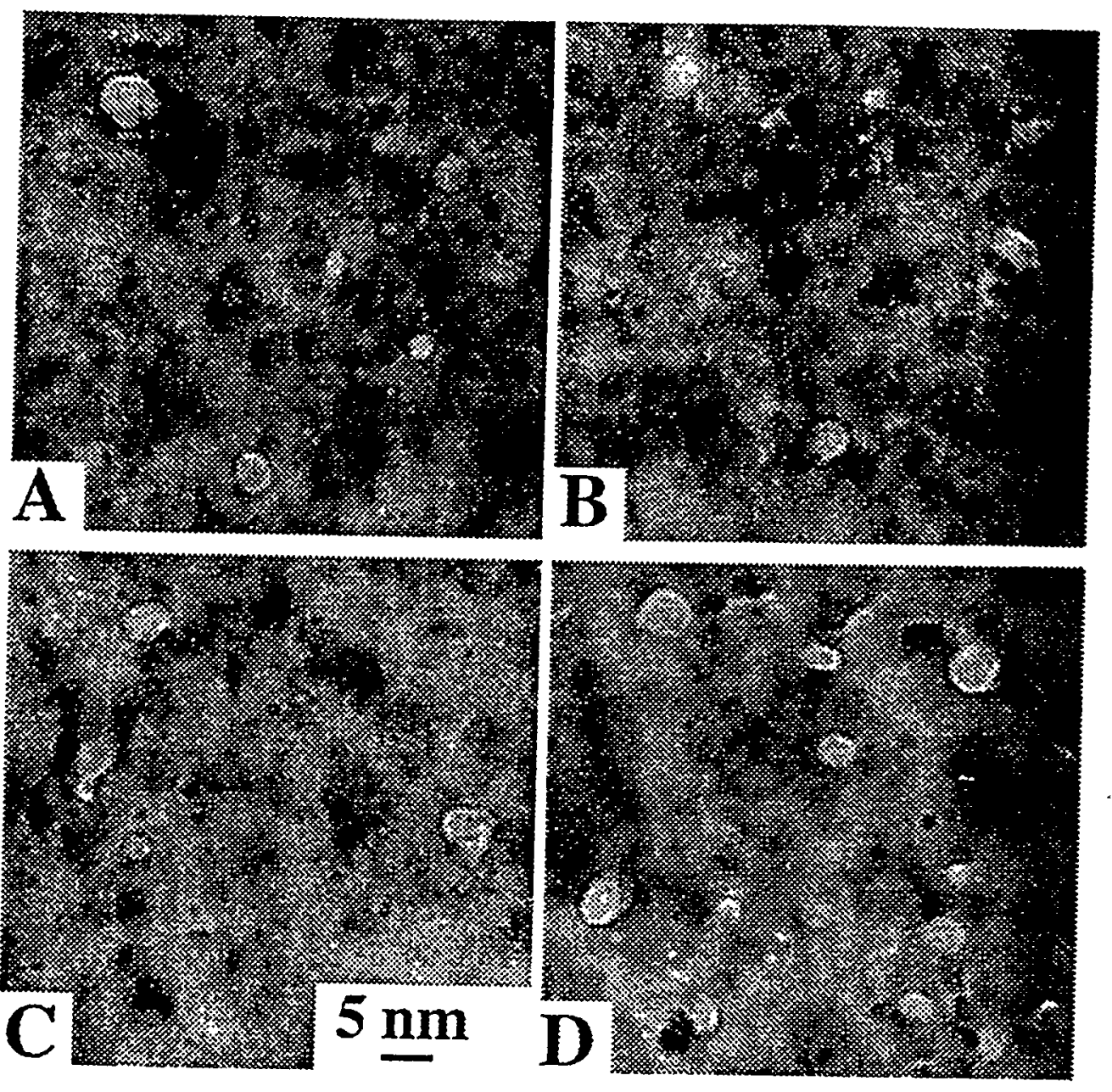

Figure 5 Birtcher: Donntlly 